\title{
Review of Journal of Institute of Science and Technology, Volume 18 Number 2, 2013
}

\author{
Chet Raj Bhatta \\ Central Department of Mathematics \\ Tribhuvan University, Kirtipur, Kathmandu \\ Email:crbhatt@yahoo.com
}

Prof. Tika Ram Aryal, who is the closest neighbor of me approached me to reviewing "Journal of Institute of Science and Technology" (IOST) Vol.18, No. 2, 2013. I thought it is immense pleasure for me to offer this short of academic job and immediately I gave the consent. He gave me a journal and I compare this issue with former issues published by IOST. I found the editorial board have brings substantial changes such as in size, setting, quality of paper, overall outlook and articles with quality work. At this juncture I must thanks to Prof. Aryal and his team for completion of this painstaking job.

This volume includes altogether 25 articles and contains two articles in "Notes" with a total of 144 pages. Being Professor of Mathematics, to review the article in multidisciplinary area was a challenging task for me even though I tried my best to study the depth of articles before review them. The journal includes article from Mathematical, Physical and Biological sciences. Out of 25 articles written, 15 articles are of single authors, 6 articles are of double authors and 4 articles are of triple authors. The positive part of this volume is some renowned authors of international repute have also contributed articles, Dean of IOST as co-authors and chief-editor and one of editorial board member also contributed articles to this issue. Another important part is involvement of various academic organizations within valley and outside. Out of 25 articles, 17 articles are contributed by Central Department of IOST, TU, whom 2 articles is contributed by North Bengal University and Bhagalpur University, India as co-authors. 6 articles are contributed by different campuses in the valley, whom one article is jointly co-authored by IOE, Pulchowk and Malardalen University, Sweden, 1 article is received by out of valley campuses and one article is written jointly by authors of Central Department of Botany and School of Natural Resources and Bio-environment (P) Ltd, Kathmandu.

So far as the length of published articles is concerned, 3 articles are of 9 pages, and is the longest articles, 3 articles are of 3 pages is of the shortest length and remaining articles are ranging 4 to 7 pages. Out of 25 articles, 20 articles contain data/table/graph/ figure etc and 5 articles do not contain any table and graph.

Among 25 articles that has been included in this volume, some of them reflects much innovative idea and originality in their article and rest others also maintain the norms of research article but it should be improved in the line of research in the days ahead.

On the other hand it's my duty to suggest the editorial board to improve the quality of this journal as the need of nation in the arena of Science and Technology. I found some articles have been included by advisor, chief executive editor and editors in this issue is naturally good enough to make much weighty but I don't find such practices in international journals. There is no uniformity in the correspondence address such as I found somewhere it is denoted by $*$ and some places denoted by 1,2 . Even there is no uniformity in email address in terms of single and multiple authors. I suggest to mention the received, revised and accepted date in the manuscript. Different font found in Keywords (only few articles), variations found in AMS Subject Classifications in Mathematics. Application of model has been written instead of result and discussion in Laxman Kumar Regmi's paper.

Finally, the editorial board has done marvelous work to improve the quality of JIST. I am pretty sure that the days ahead will bring forthcoming issues with high quality research paper on national interest and spread message to the young researchers pursue good research and contribute society and nation. 